\title{
Performance of Low-Volume Roads with Wearing Course Layer of Silty Sandy Soil Modified with Rice Husk Ash and Lime
}

\author{
Leonardo Behak \\ Assistant Professor, Departamento de Ingeniería Geotécnica, Facultad de Ingeniería, \\ Universidad de la República, Uruguay \\ Marcos Musso \\ Assistant Professor, Departamento de Ingeniería Geotécnica, Facultad de Ingeniería, \\ Universidad de la República, Uruguay
}

\begin{abstract}
Rice husk ash (RHA) is a by-product of rice milling. Its use as soil stabilizer is a way to replace the final disposal with environmental benefit. However, RHA is not cementitious itself but when mixed with lime forms cements which improve the soil properties. A research of performance of a silty sandy soil modified with RHA and lime as wearing course layer of low-volume roads was conducted through two full-scale test sections with different pavements built in Artigas, northern Uruguay. The alkaline reactivity of RHA is low because the husk burning is not controlled. The soil-RHA-lime mix design was conducted according to the Thompson's Method. The pavement test sections were monitored through deflection measures by Benkelman beam and observations of surface condition. The deflections decreased over time in both test sections due to the development of cementation of the study materials. After one year, the dust emission was reduced, the wet skid resistance of pavement surfaces improved and there was not rutting. The researched pavements have had a good performance under the existing traffic and environmental conditions, demonstrating that wearing course layer of silty sand modified with RHA and lime is an alternative to improve the condition of low-volume roads and to replace the final disposal of RHA, with environmental, social and economic benefits.
\end{abstract}

Key Words: Pavements, Soil Modification, Rice Husk Ash

\section{INTRODUCTION}

Rice husk ash (RHA) is a by-product resulting from the rice husk burning. About $10^{8}$ tonnes of rice husk are annually generated in the world (Alhassan and Mustapha, 2007) and it is about 375,000 tonnes per year in Uruguay (Behak and Núñez, 2013). Considering that about $20 \%$ in weight of rice husk remains as ash (Juliano, 1985), it could be estimated that about $2 \times 10^{7}$ tonnes and 75,000 tonnes of RHA per year would be generated around the world and in Uruguay respectively. An alternative to the final disposition of such volume of waste is 
to revalue the RHA with environmental, social and economic benefits.

Pozzolanas are siliceous and/or aluminous materials, which in themselves possess little or no cementing property, but chemically react with calcium hydroxide, such as lime, to form compounds possessing cementitious properties (Malhotra and Mehta, 1996). The RHA contains around $90 \%$ of silica (Juliano, 1985), which is the highest concentration of all plant residues (Boateng and Skeete, 1990). Based upon this, RHA has been used to improve properties of soils (Ali et al., 1992; Rahman, 1986; Muntohar and Hantoro, 2000; Basha et al., 2005; Behak and Núñez, 2008; Behak and Núñez, 2013).

Soil stabilisation by the addition of RHA and lime is particularly attractive for road pavements because it leads to cheaper construction and lesser disposal costs, reduces environmental damage and preserves the most highly qualified materials for priority use (Ali et al., 1992). Stabilisation of sandy-silty soils with RHA and lime reduces building costs, particularly in rural counties (Basha et al., 2005). Behak and Núñez (2008) observed that the treatment with RHA and lime of a sandy soil leads to a material more resistant and durable, and less deformable, and suitable as base and sub-base layers of low-volume roads.

The type of ash suitable for the pozzolanic reactivity is amorphous rather than crystalline (James and Rao, 1986). Also, the organic content of the RHA influences the stabilisation process, retarding the reactions and producing low increases of strength, due to the avidity of carbon by water and calcium ions interferes into reactions between calcium ions and amorphous silica (Petry and Glazier, 2005). When the rice husk is burned in open heap or in conventional oven, low reactivity RHA with crystalline ash and organic is produced (Mehta, 1975, Behak and Núñez, 2013). However, they have been observed strength gains in soils treated with RHA from no controlled burning at open-heap or into ovens (Rahman, 1986; Ali et al., 1992; Muntohar and Hantoro, 2000; Behak and Núñez, 2008).

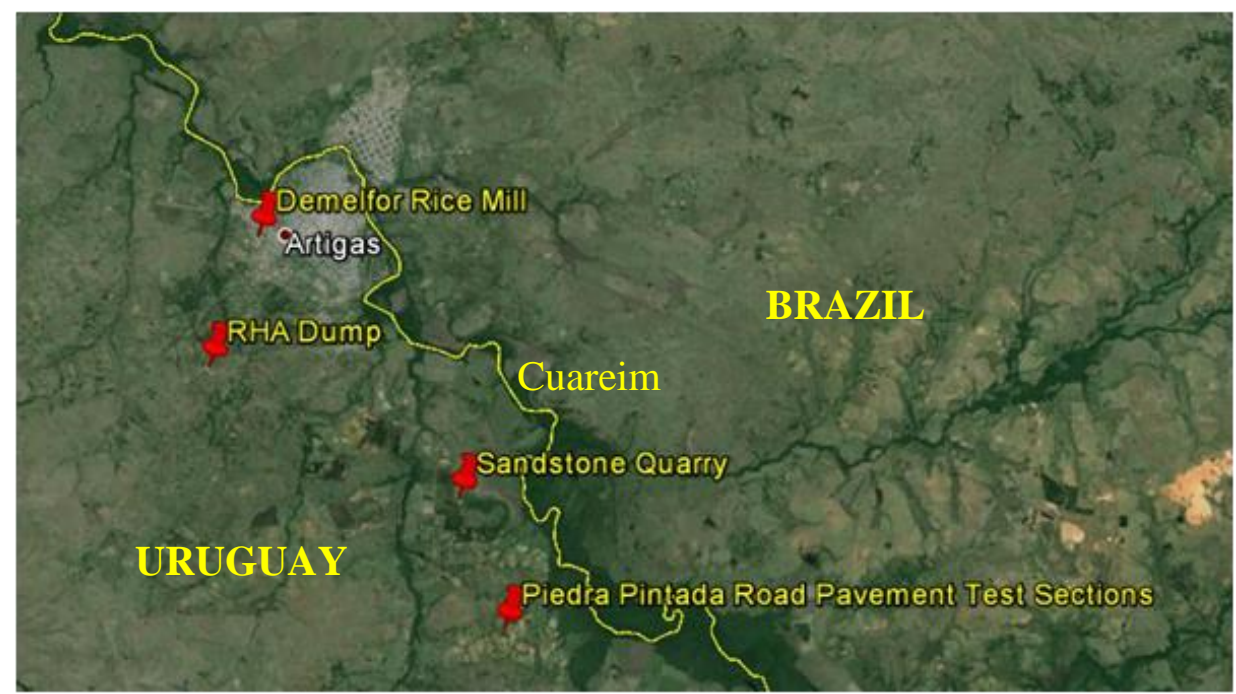

Figure 1 - Site of implementation of full-scale pavement test sections

Nevertheless, it is a lack of information concerning the performance of pavement with materials of soils treated with RHA. Therefore, a research of performance of a silty sandy soil modified with RHA and lime as wearing course layer of low-volume roads was 
conducted through two full-scale pavement test sections implanted in Piedra Pintada Road, nearest of Artigas, northern Uruguay, as is shown in Figure 1. Piedra Pintada is a low-volume road, mainly traveled by cars and pickups and, occasionally, by single rear axel trucks. The pavement is conformed by a wearing course of reddish silty sand, $10 \mathrm{~cm}$ to $15 \mathrm{~cm}$ in thick, over a subgrade of reddish silty sandy soil, similar than that of wearing course. The performance of test sections was monitored during its first year of service.

\section{MATERIALS}

\subsection{Rice Husk Ash}

The RHA was collected in a dump of Demelfor Mill, located south of Artigas (Figure 1) and a transport distance to the implantation site of the test sections of $16.5 \mathrm{~km}$. It is a waste from the no controlled burning of rice husk in conventional oven of Demelfor Mill, located in Artigas (Figure 1), resulting in a black ash with sheep appearance and remains of no burned husk. The silica of this RHA would be crystalline in high degree (Mehta, 1975, Behak and Núñez, 2013).

The mean organic content, determined through loss on ignition tests (Standard ASTM D7348) of samples burned into a muffle furnace at $550^{\circ} \mathrm{C}$ during $3 \mathrm{~h}$., is of $39 \%$. However it is affected by the presence of unburned rice husk. Due to its relatively high organic content and partially crystalline structure, the RHA from Demelfor Mill is of low reactivity.

\subsection{Soil}

The soil was extracted from a quarry in operation that is located northwest of the site of implantation of the research, at $6 \mathrm{~km}$ of transport distance (Figure 1). It was characterized in laboratory through grain size analysis test (ASTM D422), Atterberg limits (ASTM D4318). From Table 1, where are depicted the characterization results, the soil is predominantly fine sand with a low fraction passing the \#200 sieve and, according to the Unified Soil Classification System (USCS), it is a poor graduated silty sand (SP-SM).

\begin{tabular}{|c|c|}
\hline Property & Value \\
\hline Passing \#4 $(4.76 \mathrm{~mm})$ & $100 \%$ \\
\hline Passing \#10 $(2 \mathrm{~mm})$ & $99 \%$ \\
\hline Passing \#40 $(0.42 \mathrm{~mm})$ & $78 \%$ \\
\hline Passing \#200 $(0.074 \mathrm{~mm})$ & $6 \%$ \\
\hline Plasticity Index & No Plastic \\
\hline USCS Classification & SP-SM \\
\hline
\end{tabular}

Table 1 - Physical properties and classification of soil

\subsection{Lime}

A commercial calcic lime, consisting of $66 \%$ calcium oxide, $5 \%$ magnesium oxide and traces 
of silica and ferric oxide; was used. The lime is fine with $100 \%$ passing the \#40 sieve and $93 \%$ the \#200 sieve. The silt fraction is the $91 \%$ of the total dry mass.

\section{DESIGN OF PAVEMENT TEST SECTIONS}

\subsection{Design of Soil-RHA-Lime Materials}

The design of soil-RHA-lime materials was conducted using optimal criterion established by Thompson (1966). Cylindrical specimens, $3.72 \mathrm{~cm}$ in diameter and $7.65 \mathrm{~cm}$ in high, of soil with $15 \%, 20 \%$, and $25 \%$ of RHA, by dry weight of soil, and $3 \%$ and $5 \%$ of lime, by dry weight of soil, were compacted into a metallic mould by kneading system at maximum dry density and optimum moisture of modified Proctor compaction test (AASHTO T180), 1 $\mathrm{h}$ after mixing of materials and distilled water.

Compacted specimens were enveloped in polyvinyl film and cured up to 28 days at room temperature in a moisture chamber. Finally, they were subjected to unconfined compression strength tests (UCS) up to failure, according to AASHTO T208, in a triaxial load press. As control, specimens of natural soil were also tested. Results are depicted in Figure 2.

\section{Figure 2 - Unconfined compression strength as function of RHA and lime contents}

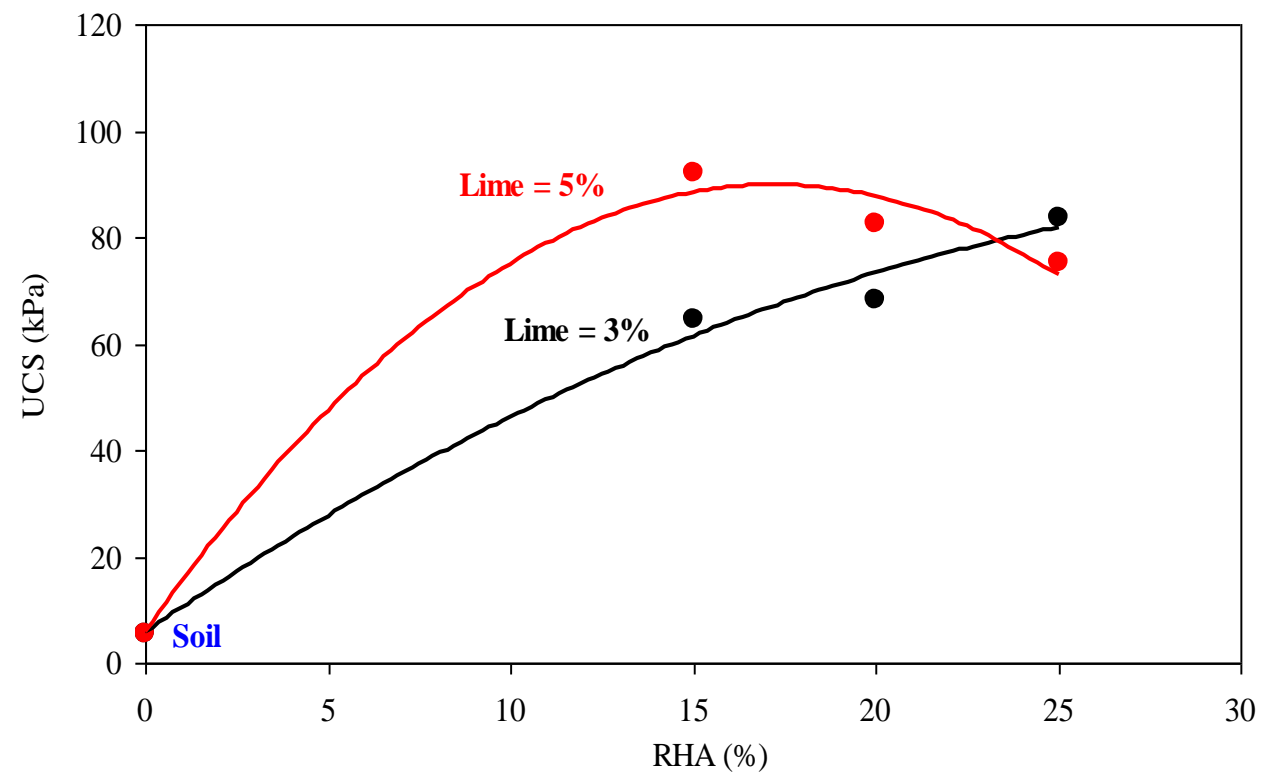

The UCS of all mixtures is greater than the soil $(5 \mathrm{kPa})$. Despite the RHA reactivity is low, it is enough to react with the lime to form a cement after 28 days (Behak and Núñez, 2008), which bonds soil grains with strength gain. For $5 \%$ of lime, UCS increases with RHA increasing up to reach a maximum value of $88 \mathrm{kPa}$ for a $15 \%$ of RHA, after which increasing of ash percentages lead to strength reducing. While $3 \%$ of lime, UCS continuously increases with RHA increasing for all the range used, so that it is greater for $3 \%$ of lime ( $82 \mathrm{kPa})$ than for $5 \%$ of lime $(73 \mathrm{kPa})$ for $25 \%$ of RHA.

Thompson (1966) suggested a minimal UCS of $345 \mathrm{kPa}$ for consider the soil as stabilized, 
which was not reached in the study case. Then, to design the soil-RHA-lime base it was considered the dosage of materials that provides maximal UCS for a minimal lime content, corresponding to a silty gravel with $25 \%$ of RHA and $3 \%$ of lime (S-25\%RHA-3\%L).

\subsection{Pavement Design of Test Sections}

Two test sections were designed, both with $15 \mathrm{~cm}$-thick base of S-25\%RHA-3\%L but with different pavements. In both sites of implantation, the existing pavement was similarly structured by a $10-15 \mathrm{~cm}$ thick base of reddish silty sand over a subgrade of reddish silty sandy soil. One pavement was designed with the modified material base over the pre-existing pavement (reinforce base), named as Reinforced Test Section The reddish silty sand is the same from the Sandstone Quarry, so the other pavement was designed with a base of the preexisting silty sand modified with RHA and lime over the subgrade soil (Single-Layer Test Section). Also, It was designed in both pavements thin surface covering layers of coarse material in order to reduce dust emissions.

\section{PERFORMANCE OF PAVEMENT TEST SECTIONS}

\subsection{Construction}

$80 \mathrm{~m}$-long test sections were built in May of 2014. The soil modified base layer of the SingleLayer Test Section was constructed firstly spreading the RHA and lime over the silty sandy base and then scarifying the pre-existing base material. Mixture of soil, RHA, lime and water was made through successive passes of motor grader in both test sections up to observe homogenisation. Finally, the compaction was conducted with smooth vibrator roller. Both test sections were released to traffic immediately after finished the work.

\subsection{Performance Monitoring}

Performance of pavements was studied through monitoring of functional and structural condition conducted at work ending (0 day) and 104 days, 195 days and 315 days of service. The structural condition was evaluated through deflexion measurements with Benkelman beam (AASHTO T256) in three fixed points of each test section, spaced $20 \mathrm{~m}$. Deflexions were also measured in fixed points outside the test sections, with traditional pavement, as control (Control Point, CP).

Deflexion of the single-layer and reinforced pavement decreases over time, as is depicted in Figure 3, with a high decreasing ratio at start times that also decreases over time so the deflexion tends to a constant value of $70 \times 10^{-2} \mathrm{~mm}$ after the first service year. Since the deflexion is associated with the pavement stiffness, that of test pavements increases in the first year and then tends to be constant. The deflexion of traditional pavement $(\mathrm{CP})$ remains constant during the same time, so the deflexion decrease in both test sections is due to the 
stiffening of S-25\%RHA-3\%L material given by the development of its cementation that is time dependant.

\section{Figure 3 - Deflexions of pavement tests and traditional pavements as function of time}

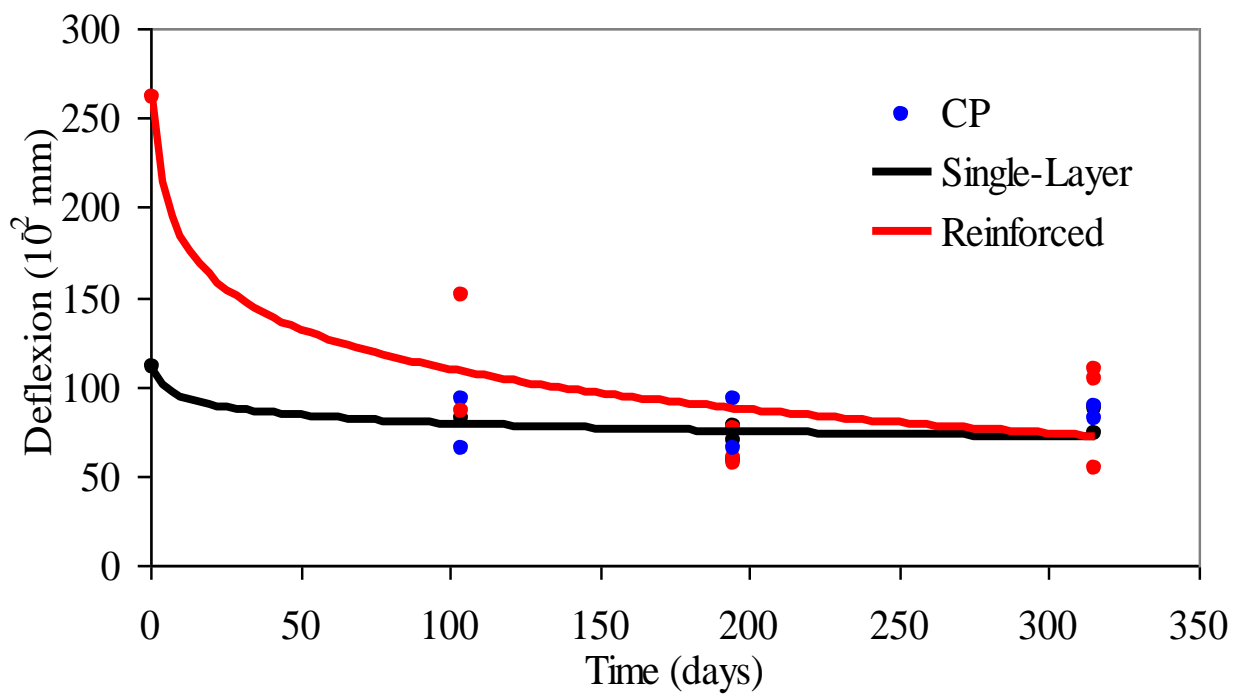

The initial deflexion of reinforced pavement is greater than that of the single-layer pavement but it tend to be similar in both pavements at the end of the analysed period. Before cementation starting in the modified material, test pavements are less stiff than the traditional pavement, however those deflexions tend to be less than this at 315 days and, then, test pavements have better structural condition.

The functional condition was evaluated through surface visual observations. Initially, the deformability under heavy load of the soil modified with $25 \%$ of RHA and $3 \%$ of lime was appreciable. When its cementation develops, the deformability reduces so that it is not already appreciable at 104 days. The dust emission was low, demonstrating that a thin cover layer of gravel is enough to mitigate it up to admissible degrees.

Transit tests conducted on test and traditional pavements in wet conditions show that the treatment of the soil with RHA and lime considerably improve it wet skid resistance, so it is practically eliminated. After nearly 2 years, it were developed potholes of low severity and extent and it is not observed neither surface cracks nor rutting.

\section{CONCLUSIONS}

The RHA from the no controlled burning of rice husk in Demelfor Mill is of low alkaline reactivity due to its high crystalline silica and organic content. However, it is a waste that must be used in order to reduce volumes of final disposition and, therefore, the environmental impact.

Despite its low reactivity, the unconfined compression strength (UCS) increases when the silty sand is treated with different RHA and lime percentages. Amorphous silica of RHA react with calcium ions of hydrated lime to form cementitious products that bound soil 
particles with UCS gain. This increase is observed up to a given percentage of RHA from which the RHA in excess does not react causing loss of strength. The soil-RHA-lime material designed for the bases of pavement test sections was that provides maximal UCS for a minimal lime content, corresponding to a silty gravel modified with $25 \%$ of RHA and $3 \%$ of lime.

The performance of the full-scale pavement test sections with similar $15 \mathrm{~cm}$-thick base layer of soil-RHA-lime but different pavements was similar in the first year of service. The soil modified with $25 \%$ of RHA and $3 \%$ of lime develops stiffness in the first months due to the cementation caused by the products of reactions between the silica of the RHA and calcium ions of the lime. This occurs in spite of the low reactivity of the used RHA and the studied pavements were subjected to transit loads once finished the work. The structural condition of pavements improves over time at least during the first year. Neither surface cracks nor rutting are observed after 20 moths, which means that both studied pavements would be far from the failure.

The dust emission of soil-RHA-lime material can be controlled with a thin surface coating layer of coarse material. It is advisable to roll the coarse material once spread in order to avoid its wear loose.

Pavements with base layer of soil modified with RHA and lime present a good performance after 20 moths for a low-volume road and it is better than that of traditional pavements structured by a base layer silty sand over a subgrade soil. It is an economic alternative because it uses a waste material, such is the RHA, and improves the pavement performance with reducing of maintenance and rehabilitation costs. It is an environmentally right solution due to allows reducing final disposition volumes of RHA.

\section{ACKNOWLEDGMENTS}

The Authors wish to thank to the Agencia Nacional de Investigación e Innovación (ANII) of Uruguay for funding the research project. To the Intendencia Municipal de Artigas for supporting the research, mainly in the construction of the test sections. Particularly, to the Director Lidio Paniagua for the enthusiasm put to good project completion. Finilly, we would like to thank to Gustavo Piñeiro, Juan Alvez, Federica Selves and Bruno Telechea for his important collaboration.

\section{REFERENCES}

ALHASSAN, M. and MUSTAPHA, A.M. (2007). Effect of Rice Husk Ash on Cement Stabilized Laterite. Leonardo Electronic Journal of Practices and Technologies 6(11), pp. 47-58.

ALI, F.H.; ADNAN, A. and CHOY, C. K. (1992). Geotechnical Properties of a Chemically Stabilized Soil from Malaysia with Rice Husk Ash as an Additive. Geotechnical and Geological Engineering 10(2), pp. 117-134, Amsterdam.

BASHA, E. A.; HASHIM, R.; MAHMUD, H. B. and MUNTOHAR, A. S. (2005). 
Stabilization of Residual Soil with Rice Husk Ash and Cement. Construction and Building Materials 19, pp. 448-453.

BEHAK, L. and NÚÑEZ, W.P. (2008). Caracterización de un Material compuesto por Suelo Arenoso, Ceniza de Cáscara de Arroz y Cal Potencialmente útil para su uso en Pavimentación. Revista de Ingeniería de Construcción 23(1), pp. 34-41, Santiago de Chile. BEHAK, L. and NÚÑEZ, W.P. (2013). Effect of Burning Temperature on Alkaline Reactivity of Rice Husk Ash with Lime. Road Materials and Pavement Design 14(3), pp. 570-585, London.

BOATENG, A. A. and SKEETE, D. A. (1990). Incineration of Rice Hull for Uses as a Cementitious Material. The Guyana Experience. Cement and Concrete Research 20(5), pp. 795-802.

JAMES, J.; RAO, S.M. (1986). Reactivity of Rice Husks Ash. Cement Concrete Research 16, pp. 296-302.

JULIANO, B.O. (1985). Rice: Chemistry and Technology. American Association of Cereal Chemists.

MALHOTRA, V.M. and MEHTA, P.K. (1996). Pozzolanic and Cementitious Materials. Gordon and Breach.

MEHTA, P. K. (1975). Rice Hull Ash Cement: High-Quality, Acid Resisting. ACI Journal, pp. 235-236.

MUNTOHAR, A. S. and HANTORO, G. (2000). Influence of Rice Husk Ash and Lime on Engineering Properties of a Clayey Subgrade. Electronic Journal of Geotechnical Engineering, p. 12.

PETRY, T.M. and GLAZIER, E.J. (2005). The Effect of Organic Content on Lime Treatment of Highly Expansive Clay. 2nd International Symposium on Treatment and Recycling of Materials for Transport Infrastructure, Paris.

RAHMAN, M. A. (1986). The Potential of Some Stabilizers for the Use of Lateritic Soil in Construction. Building and Environment Journal 21(1), pp. 57-61.

THOMPSON, M.R. (1966). Lime Reactivity of Illinois Soils. Journal of Soil Mechanics and Foundations Division 92, pp. 67-92. 